ARTICLE

Received 24 Nov 2015 | Accepted 13 Jul 2016 | Published 23 Aug 2016

DOI: $10.1038 /$ ncomms12558

OPEN

\title{
Sixteen years of change in the global terrestrial human footprint and implications for biodiversity conservation
}

Oscar Venter 1,2,3, Eric W. Sanderson ${ }^{4}$, Ainhoa Magrach ${ }^{5,6}$, James R. Allan ${ }^{2,7}$, Jutta Beher ${ }^{2}$, Kendall R. Jones ${ }^{2,7}$, Hugh P. Possingham ${ }^{2,8}$, William F. Laurance ${ }^{3}$, Peter Wood ${ }^{3}$, Balázs M. Fekete ${ }^{9}$, Marc A. Levy ${ }^{10}$

\& James E.M. Watson ${ }^{4,7}$

Human pressures on the environment are changing spatially and temporally, with profound implications for the planet's biodiversity and human economies. Here we use recently available data on infrastructure, land cover and human access into natural areas to construct a globally standardized measure of the cumulative human footprint on the terrestrial environment at $1 \mathrm{~km}^{2}$ resolution from 1993 to 2009 . We note that while the human population has increased by $23 \%$ and the world economy has grown $153 \%$, the human footprint has increased by just $9 \%$. Still, $75 \%$ the planet's land surface is experiencing measurable human pressures. Moreover, pressures are perversely intense, widespread and rapidly intensifying in places with high biodiversity. Encouragingly, we discover decreases in environmental pressures in the wealthiest countries and those with strong control of corruption. Clearly the human footprint on Earth is changing, yet there are still opportunities for conservation gains.

\footnotetext{
${ }^{1}$ Ecosystem Science and Management Program, University of Northern British Columbia, Prince George, British Columbia, Canada V2N 4Z9. ${ }^{2}$ Centre for Conservation and Biodiversity Science, The University of Queensland, St Lucia Queensland 4072, Australia. ${ }^{3}$ Centre for Tropical Environmental and Sustainability Science, College of Science and Engineering, James Cook University, Cairns, Queensland 4878, Australia. ${ }^{4}$ Wildlife Conservation Society, Global Conservation Program, Bronx New York 10460, USA. ${ }^{5}$ Ecosystem Management, ETH Zurich, 8092 Zurich, Switzerland. ${ }^{6}$ Doñana Biological Station (EBD-CSIC), Avd. Américo Vespucio s/n, Isla de la Cartuja, 41092 Sevilla, Spain. ${ }^{7}$ School of Geography, Planning and Environmental Management, University of Queensland, St Lucia Queensland 4072, Australia. ${ }^{8}$ Department of Life Sciences, Imperial College London, Silwood Park, Ascot, Berkshire SL5 7PY, UK. ${ }^{9}$ Department of Civil Engineering, The City College of New York, CUNY Environmental CrossRoads Initiative, City University of New York, New York, New York 10007, USA. ${ }^{10}$ Center for International Earth Science Information Network, Columbia University, Palisades, New York 10964, USA. Correspondence and requests for materials should be addressed to O.V. (email: venter@unbc.ca).
} 
H umanity and nature form a coupled system ${ }^{1}$. The ecological capital and ecosystem services provided by nature underpin our social and economic systems ${ }^{2}$, and we in turn apply pressure on these natural systems through our extraction of natural resources, the proliferation of our infrastructures and our conversion of natural habitats to production land uses ${ }^{3}$. There is mounting evidence that human demands on natural systems are accelerating and could be undermining the stability of these systems ${ }^{4}$. A pervasive failure to mitigate these impacts is now resulting in widespread biodiversity declines $^{5,6}$ and reductions in the benefits humans receive from natural systems ${ }^{2}$.

Understanding the spatial and temporal patterns in human pressures on the environment provides a foundation for mitigating environmental damage in sensitive or ecologically valuable areas. Human pressures on the environment, commonly referred to as threats to biodiversity, are the actions taken by humans with the potential to harm nature ${ }^{7}$. Recent advances in remote sensing have allowed unprecedented advances in mapping human pressures from habitat conservation through time, especially for forested landscapes ${ }^{8}$. However, many forms of human pressure on the environment, such as our extensive roads and pasture lands, are harder to detect than outright habitat conversation, and often overlooked by space-borne satellites ${ }^{9}$. Cumulative threat mapping aims to surmount this limitation by including a range of human pressures within a framework that couples top-down remote sensing with data collected bottom-up via surveys ${ }^{10}$.

A range of cumulative threat maps have been developed at regional $^{11}$ and global scales ${ }^{12,13}$. The Human Footprint, first released in 2002 based on data from the early 1990s (ref. 14), is unique for considering eight human pressures globally, making it the most complete and highest-resolution globally consistent terrestrial data set on cumulative human pressures on the environment.

Terrestrial maps of cumulative human pressures have proved to be better predictors of the range sizes of species than their biological traits, such as body size and trophic level ${ }^{15}$, and to be a strong predictor of modern range collapses ${ }^{16}$, the threat status of species $^{17}$, site-scale species richness ${ }^{18}$, and species population size and dispersal ability ${ }^{19}$. Cumulative pressures are also associated with invasibility ${ }^{20}$. With calls for rapid action to prevent collapse of planetary ecological systems ${ }^{21}$, we need to better understand spatial and temporal trends in human pressures and their related consequences, so we can act accordingly.

Here we use the human footprint framework to compile remotely sensed and bottom-up survey information on eight variables measuring the direct and indirect human pressures on the environment in 1993 and 2009. We included data on the following: (1) extent of built environments; (2) crop land; (3) pasture land; (4) human population density; (5) night-time lights; (6) railways; (7) roads; and (8) navigable waterways. These pressures were weighted according to estimates of their relative levels of human pressure following Sanderson et al. ${ }^{14}$, and then summed together to create the standardized human footprint for all non-Antarctic land areas. The primary aims of this study are to update the original human footprint map to provide a contemporary view of human pressures, and to create the first temporally consistent maps of the human footprint, such that patterns of change over time can be analysed. In addition to these aims, we perform a number of preliminary analyses determinants of important spatial and temporal patterns in the human footprint, and we discuss a number of remaining unanswered questions for subsequent focused analyses. Broadly, our analyses reveal that the human footprint is widespread and rapidly increasing, especially in tropical ecoregions and other locations rich in biodiversity. Wealthy nations and those with strong control of corruption showed some signs of improvements, yet this is overshadowed by the fact that $71 \%$ of global ecoregions saw marked ( $>20 \%$ ) increases in their human footprints.

\section{Results}

The global human footprint. We find that in 2009, the world's land areas had an area-weighted average human footprint score of 6.16 (out of a maximum of 50; Table 1), which is an increase of 9\% from 1993 levels. These pressures show strong spatial variation. The highest pressure biomes include the temperate broadleaf forests of Western Europe, eastern United States and China, and the tropical dry forests of India and parts of Brazil, and parts of Southeast Asia's tropical moist forest (Fig. 1a). Areas of no measureable human footprint (as mapped by our eight pressures) persisted over $\sim 27 \%$ of the world's non-Antarctic land area in 1993. But these areas of intact habitats have decreased rapidly over the past two decades, with 23 million $\mathrm{km}^{2}$ (9.3\%) experiencing an incursion of human pressures. The remaining pressurefree lands are concentrated in the boreal and tundra biomes, the Sahara, Gobi and Australian deserts, and the most remote moist tropical forests of the Amazon and Congo Basins.

Averaging over the 823 ecoregional boundaries provides an overview of change in the human footprint from 1993 to 2009 (Fig. 1b). Most ecoregions are undergoing increases in average footprint values $(n=573)$, especially in tropical regions such as Southeast Asia and eastern Brazil, while some ecoregions appear

Table 1 | Human pressures used to construct the human footprint (HF).

\begin{tabular}{|c|c|c|c|c|}
\hline \multirow[t]{2}{*}{ Data set } & \multirow[t]{2}{*}{ Timing } & \multirow[t]{2}{*}{ Years } & \multicolumn{2}{|c|}{ Mean HF score } \\
\hline & & & 1993 & 2009 \\
\hline Built environments & Dynamic & 1994, 2009 & 0.17 & 0.19 \\
\hline Crop lands & Dynamic & 1992,2005 & 0.79 & 0.96 \\
\hline Pasture lands* & Static & 2000 & 0.51 & 0.47 \\
\hline Population density & Dynamic & 1990, 2010 & 2.10 & 2.32 \\
\hline Night lights & Dynamic & 1993, 2009 & 0.29 & 0.36 \\
\hline Railways & Static & $1960 s-1990 s$ & 0.15 & 0.15 \\
\hline Major roadways & Static & 1980-2000 & 1.32 & 1.32 \\
\hline Navigable waterways & Dynamic & 1993, 2009 & 0.33 & 0.38 \\
\hline All combined & NA & NA & 5.67 & 6.16 \\
\hline
\end{tabular}




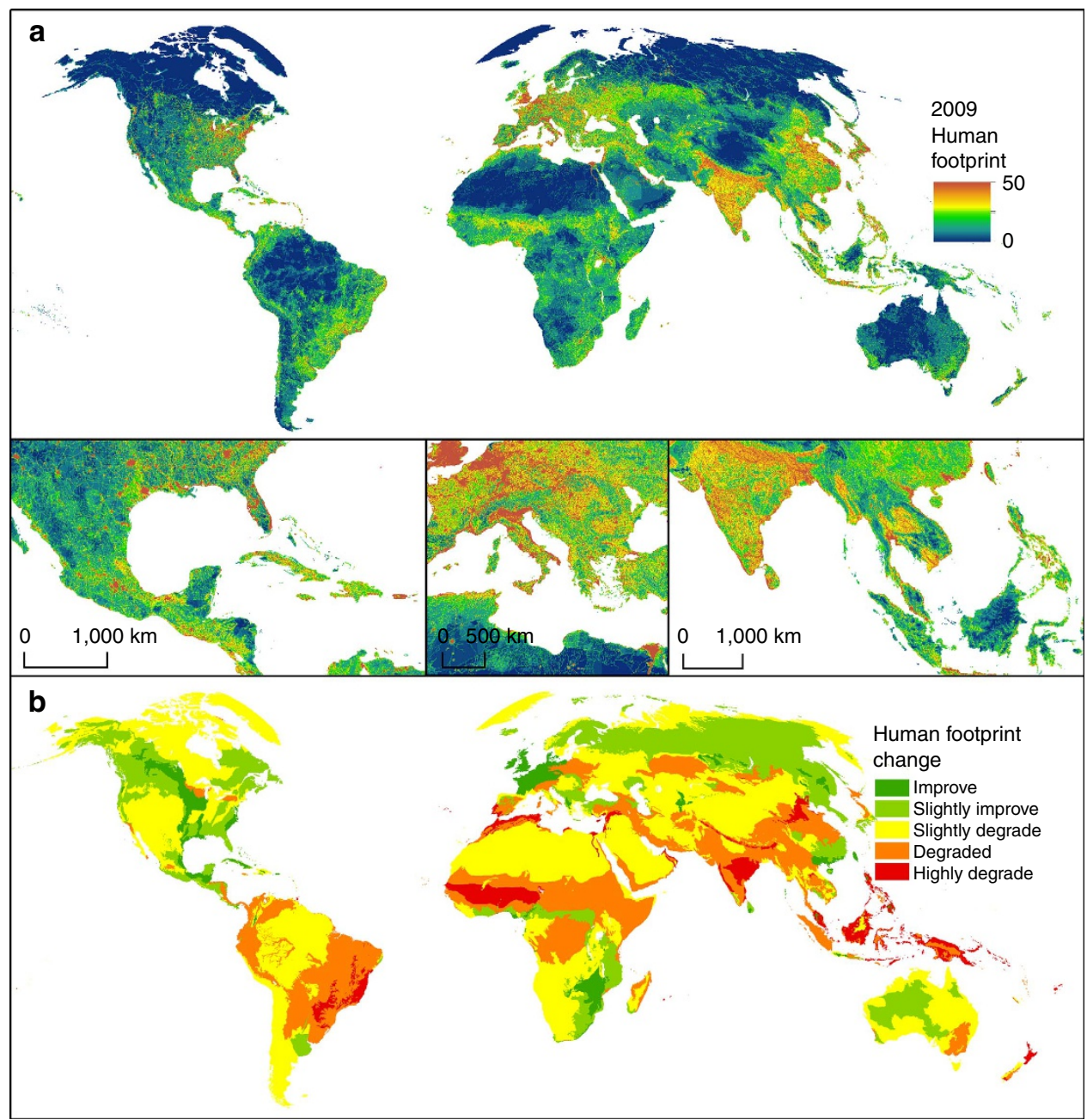

Figure 1 | Maps showing the current state and recent change in the global human footprint. (a) The global human footprint map for 2009 using a 0-50 cool to hot colour scale, and (b) absolute change in average human footprint from 1993 to 2009 at the ecoregion scale ${ }^{74}$. Data on human footprint change are summarized by ecoregions to allow for interpretation of broad patterns. Inset panels in $\mathbf{b}$ show focal regions that span the full breadth of the human footprint pressure scale.

to be improving $(n=223)$, primarily in temperate zones such as North America and Western Europe. These patterns would indicate that change may be underway in divergent trajectories across space, with important ramifications for biodiversity.

Only $3 \%$ of 772 ecoregions saw declines in human pressure $>20 \%$, whereas $71 \%$ saw average increases of $20 \%$ or more (Fig. 2). Examining ecoregions of least $1,000 \mathrm{~km}^{2}$ in extent, average human footprint decreased in some temperate forests and grasslands in the Northern hemisphere (for example, Northern transitional alpine forests, $-65 \%$; Canadian aspen forests and parklands, $-38 \%$; Central tall grasslands, $-30 \%$; and Caledon conifer forests, $-30 \%$ ) and in selected tropical montane forests (for example, peninsular Malaysian montane rain forest, $-40 \%$; Belizean pine forests, $-33 \%$; and Sri Lankan montane rain forests, $-32 \%$.) In contrast, pressures more than doubled in 20 ecoregions globally, for example, in numerous North American tundra ecosystems (for example, Torngat Mountain tundra, $>+10,000 \%$; Davis Highlands, $+5,090 \%$; and Baffin coastal tundra, $+1,591 \%)$, across most forested ecoregions in New Guinea (for example, New Guinea mangroves, $+151 \%$; Southern New Guinea lowland rain forests, + 321\%; and New Britain-New Ireland lowland rain forests, $+141 \%)$ and in selected Neotropical rain forests (for example, Purus várzea, $+161 \%$; and Japura-

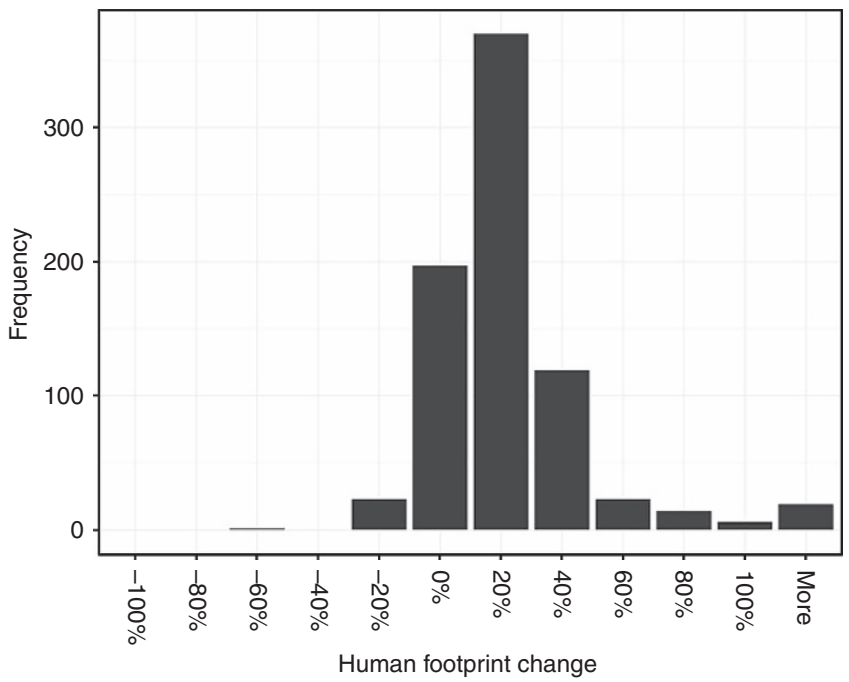

Figure 2 | Human footprint change summarized by terrestrial ecoregions. Histogram shows per cent change in average human footprint scores for the world's 823 non-Antarctic ecoregions. 
Solimoes-Negro moist forests, + 101\%). Admittedly, the largest percentage increases were seen in ecoregions with a low base level of human pressure, but these increases reinforce the point about decline of wilderness over the study period.

Our validation of the human footprint map shows there is strong agreement between the human footprint measure of pressure and pressures scored by visual interpretation of highresolution images (Supplementary Fig. 1 and Supplementary Note 1). The root mean squared error ${ }^{22}$ for 3,114 validation $1 \mathrm{~km}^{2}$ plots was 0.15 on a normalized $0-1$ scale. The Kappa statistic $^{23}$ was 0.737 , also indicating good agreement between the human footprint and the validation data set. Of the $3,1141 \mathrm{~km}^{2}$ validation plots, the human footprint scored 94 of them $20 \%$ higher than the visual score (false positive) and 263 of them $20 \%$ lower (false negative). The remaining 2,757 plots (88.5\%) were within $20 \%$ agreement. While this represents good agreement, it appears from the higher false-negative rate that the human footprint is to some extent susceptible to false negatives, where pressures are actually present in locations where the human footprint maps them as absent. The maps should therefore be considered as conservative estimates of human pressures on the environment.

Human footprint and agricultural suitability. We used data on the suitability of land for agriculture ${ }^{24}$ to evaluate the relationship between the human footprint trends and agricultural suitability. Agricultural suitability ranges from $0 \%$ suitable to $100 \%$ suitable based on climatic and soil constraints ${ }^{24}$. While the patterns are complex, the suitability of lands for agriculture appears to be a major determinant of the intensity, extent and temporal trends of pressures across the globe. A correlation between agriculture suitability and cumulative human pressures is expected, yet the strength of this relationship is surprising. We find a near continuous linear increase in cumulative pressures with increasing agricultural suitability (Fig. 3a), with $93.8 \%$ of the variation in average footprint values explained by agricultural suitability alone (linear model, $t$-value $=38.77, P<0.001$ ).

To measure the spatial extent of the human footprint in 2009, we bin land areas into five classes of human pressure such that each bin encompasses a similar proportion ( $\sim 20 \%)$ of the planet, and label these bins, 'no pressure, mean human footprint $=0$ '; 'low pressure, human footprint $=1-2$; 'moderate pressure, human footprint $=3-5$ '; 'high pressure, human footprint $=6-11$ '; and 'very high pressure, human footprint $=12-50$ '. We find that lands of no pressures dominate in places that are fully unsuitable for agriculture (for example, deserts), but are then rapidly replaced by moderate- and high-pressure bins in areas even marginally suitable for agriculture (Fig. 3b). Pressure-free lands are almost totally lacking in locations which are at least $60 \%$ suitable for agriculture, and the extent of very-high-pressure bins increases linearly until it becomes the dominant category at around the $60 \%$ suitable for agriculture mark. The near-total dominance of very-high-pressure lands in locations most suitable for agriculture has important implications for the ecological communities associated with these areas, which we explore in the next section.

While human pressures show a consistent positive association with agricultural suitability in 2009, the change in human pressures since 1993 follows an inverted-U pattern (Fig. 3c). Similar to the least suitable areas, the most suitable areas showed little change since 1993, potentially as these areas were already saturated with pressures by then. On the other hand, moderately suitable areas, ranging from 40 to $80 \%$ suitability have experienced a rapid increase in human footprint since 1993. This pattern is likely explained by the expansion of agriculture and other human pressures into these more marginal lands.
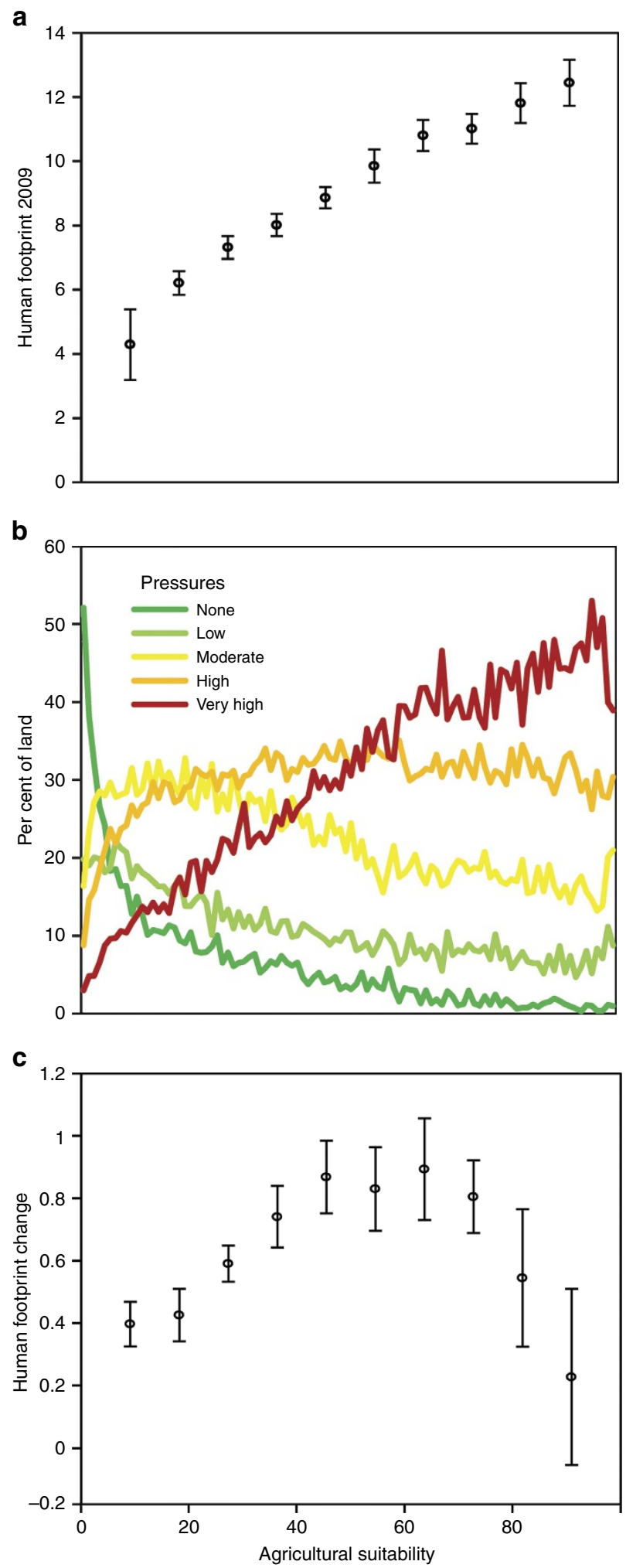

Figure 3 | Relationships between the human footprint and suitability of land for agriculture. The suitability of land and its relationship to (a) the mean and s.d. of the human footprint in 2009, (b) the spatial extent of five human footprint bins and (c) the mean change and s.d. in the human footprint. The thresholds that define the five human footprint bins in $\mathbf{b}$ are set such that each bin covers a similar proportion of the world's land areas in 2009, with higher pressure bins represented by warmer colours. 
Human footprint and biodiversity. The interaction of abiotic conditions and evolutionary history has made some places on Earth teem with life, while others are more biologically poor. Places that house large concentrations of overlapping species are particularly important for biodiversity conservation ${ }^{25}$, as their loss contributes disproportionately to the current extinction crisis. With increasingly complete data sets on the distributions of plants and animals ${ }^{26}$, we now have a reasonable idea of where species are concentrated ${ }^{26,27}$. However, comparatively little is known about the pressures facing these concentrations of biodiversity.

To determine the pressures within areas high in biodiversity we use three complementary measures of areas with high concentrations of species. First, we use biodiversity hotspots ${ }^{28}$, which are defined as areas having at least 1,500 endemic vascular plants and at least $70 \%$ of their natural vegetation cleared, and they are therefore expected to be under high pressure. To complement these plant-based areas, we also map high concentrations of vertebrates by overlaying the 21,059 range maps of terrestrial birds $^{29}$, mammals $\mathrm{s}^{30}$ and amphibians ${ }^{30}$ onto a $30 \mathrm{~km}$ grid of the world's land areas. We map high concentrations of these vertebrates as places with at least 569 vertebrates, which is the threshold that defines the richest $10 \%$ of the planet. Threatened species are most likely to go extinct in the near term, and we map threatened vertebrate concentrations as the areas with at least 14 threatened vertebrates, which is the threshold necessary to encompass $10 \%$ of land areas.

We find that biodiversity hotspots and areas that contain high numbers of threatened vertebrate species are under high human pressure (Fig. 4a,b). High- and very-high-pressure bins cover the majority of these biodiversity valuable lands. For biodiversity hotspots, only small areas of no or low human footprint still exist in the Western Australia, Tropical Andes, Northern Cerrado and Central Asian Mountain Biodiversity hotspots. For areas that contain high numbers of threatened vertebrates species, some lowpressure land still exists in the heart of Borneo and in the Central Asia Desserts between the Caspian and Aral Seas. However, areas of no pressure cover $<3 \%$ of the world's biodiversity hotpots and $2 \%$ of threatened vertebrate concentrations.

A more encouraging picture emerges when looking at the places on the planet that have the highest overall richness of birds, mammals and amphibians (Fig. 4c). The Amazon basin falls almost entirely within the $10 \%$ most species-rich land on Earth. While the Amazon is bisected in parts by navigable waterways and roads, and is increasingly encroached by settlements and industrial agriculture (especially in the southern region), much of the Amazon is still free of human pressures (Fig. 4c). Globally, there is an even distribution of human footprint categories across the areas that contain high numbers of vertebrates, which indicates remaining opportunities for a proactive approach to conservation that maintains these most-specious of ecosystems in their natural condition before pressures infiltrate them ${ }^{31}$.

While vertebrate concentrations still have extensive areas of no human pressure, these areas are disappearing at an alarming rate (Fig. 5). Our results show a rapid decline in no-pressure lands in vertebrate richness concentrations since 1993 (Fig. 5c). Human pressures expanded into intact areas holding the highest concentrations of vertebrates at a rate faster than any transition in any other area. Moreover, there were large increases in areas of high- and very-high-pressure bins, which are likely to have the greatest impacts on native biodiversity. Biodiversity hotspots and threatened vertebrate hotspots also experienced similar increases in these heavily impacted areas (Fig. 5a,b).

The human footprint and socio-economic change. The pressures underlying the human footprint are all linked in some way to socio-economic activities. These pressures include our urban centres, which are the powerhouses of the global economy, agricultural lands, transport networks and the people who are ultimately responsible for all economic output. With a human footprint that is already near ubiquitous, especially in places suitable for agricultural and high in biodiversity, and forecasts for significant population and economic growth ${ }^{32}$, it would be encouraging if the human footprint is not deterministically linked to socio-economic growth.

To investigate this, we compared the growth in the human footprint from 1993 to 2009 with population and economic changes over the same period. We note that while the human population has increased by $23 \%$ (ref. 33) and the world economy has grown by $153 \%$ (ref. 33), the human footprint has increased by just $9 \%$. It appears as though the global human economy is increasing its efficiency in the use of land resources when measured in terms of human footprint per person or per dollar gross domestic product (GDP), which is in line with findings from other studies ${ }^{34}$.

To further investigate this relationship, we quantified the change in the human footprint for countries grouped by income level. We find an inverted-U-shaped relationship for human pressure across income categories (Fig. 6), with lower-middleincome countries undergoing the greatest increase in human footprint and high-income countries undergoing the least. Moreover, we find that footprint trajectories have actually reversed in the wealthiest nations (Fig. 6, red bar). This trend is not entirely unexpected considering that environmental Kuznets curve theory posits an inverted-U-shaped relationship between economic growth and environmental degradation ${ }^{34}$.

The decrease in human pressures in wealthy countries may indicate a more environmentally sustainable future, with increased wealth and urbanization leading to reduced human footprint for some countries ${ }^{34}$. However, it is important to determine if this trend is driven by measures of socio-economic and governance conditions or rather by patterns of trade that allow some countries to transfer their demand for food and raw materials to other countries. For example, almost $40 \%$ of beef produced in the Amazon is not consumed domestically but instead exported for consumption in European Union countries ${ }^{35}$.

We investigate the link between trade and the human footprint by focusing on the top 50 percentile of countries for GDP growth per person ( $n=73$ with data available). For these rapidly expanding economies, we ask whether their highly divergent environmental outcomes, in terms of their human footprint, can be explained by variation in their rates of international trade, measured as the net trade in agricultural and forestry products, or instead by proxies for socio-economic transformation and governance. Crop and pasture lands are the greatest driver of land conversion ${ }^{36}$, and timber plantations cover 140 million hectares, with at least a further 340,000 hectares of selective logging annually ${ }^{37}$. Surveying trade in these sectors should therefore provide a reasonable approximation of whether a country is exporting its environmental pressures through international trade. This method does have a number of limitations, which are discussed further in the following section.

Of the 73 rapidly expanding economies, 47 experienced increased human pressure and 26 experienced decreased human pressure (Table 2). Net trade does not appear to be driving this divergence, as economically growing countries with declining human pressure tended to be net exporters (US\$1.3 billion or 17 million tons) while economically growing countries with increasing human pressure tended to be net importers (US $\$-1.8$ billion or -7 million tons; Table 2). Instead, environmentally improving countries are characterized by higher rates of urbanization, human development (a composite measure of health and education) and control of corruption 


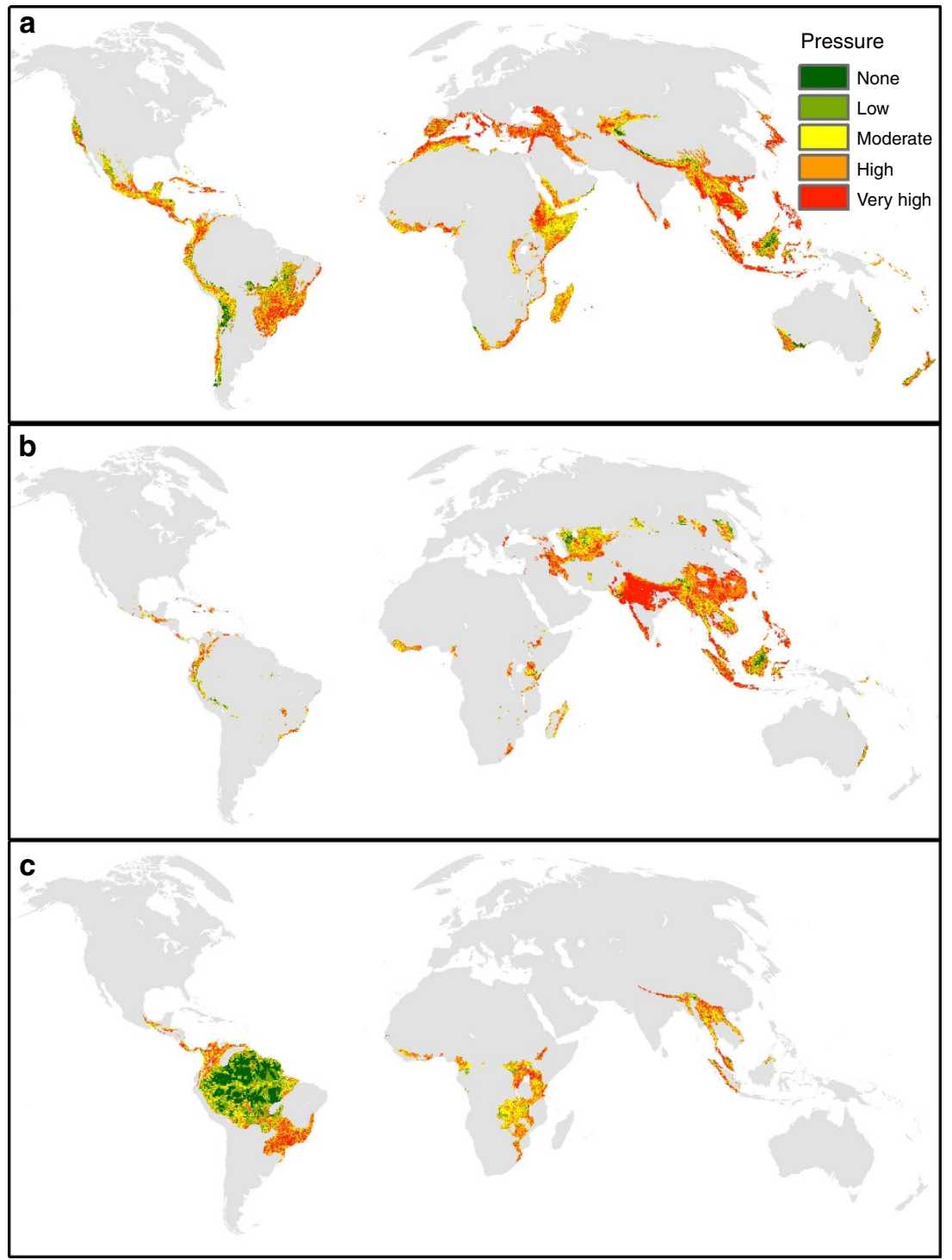

Figure 4 | The extent of the human footprint within important areas for biodiversity. The distribution of human footprint intensity bins across (a) biodiversity hotspots ${ }^{28}$, (b) high concentrations of threatened vertebrates and (c) high concentrations of all vertebrates. High concentrations are the $10 \%$ of land areas encompassing the highest global concentrations of either threatened vertebrates or all vertebrates 29,30 . Green represents areas with a human footprint score of 0 , and warmer colours represent higher-pressure bins.

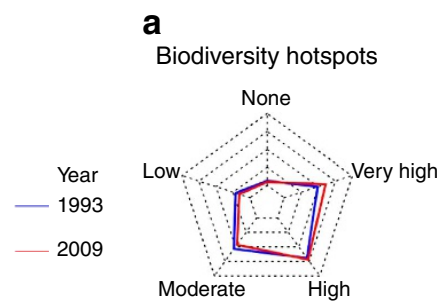

b Threatended vertebrate concentrations

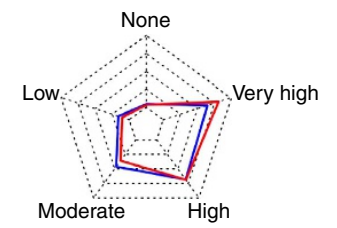

C

All vertebrate concentrations

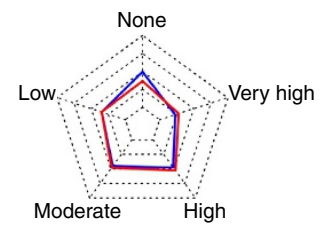

Figure 5 | Change in human footprint within important areas for biodiversity. The extent of human footprint intensity bins across (a) biodiversity hotspots $^{28}$, (b) high concentrations of threatened vertebrates and (c) high concentrations of all vertebrates for 1993 (blue lines) and 2009 (red lines).

(Table 2). A parsimonious general linear model explaining the environmental trajectories of the expanding economies includes their rate of urbanization and control of corruption (Supplementary Table 1), with only corruption being statistically significant (Supplementary Fig. 2).

\section{Discussion}

The human footprint presents a spatially explicit, temporally consistent and quantitative measure of the in situ direct and indirect human pressures on the environment. Pressures are chosen to represent some of the most important actions taken by 
humans with the potential to harm local natural systems. These pressures include measures of land cover change, such as urban and agricultural land uses, infrastructures, such as railways and electric infrastructure, and access into natural areas, such as via roads and navigable waterways. Our study presents an update to the original human footprint map ${ }^{14}$, and extends previous work by providing the first set of temporally intercomparable human footprint maps. Moreover, our validation of the human footprint map found strong agreement with an independently derived measure of human pressures.

We find strong relationships between the severity, extent and expansion of the human footprint and the suitability of land for agriculture. The high pressures facing much of the planet highlights the urgent need for enhanced conservation interventions. Some of the hardest decisions about protecting natural landscapes must be taken within the planet's most biologically valuable regions. While remote sensing has estimated biodiversity hotspots to have around $15 \%$ natural vegetation remaining ${ }^{38}$, our results suggest that opportunities for conservation may be much constrained, with only $3 \%$ of these areas currently free of human pressures. This result indicates that maintaining biodiversity will require extensive restoration to remove and mitigate existing

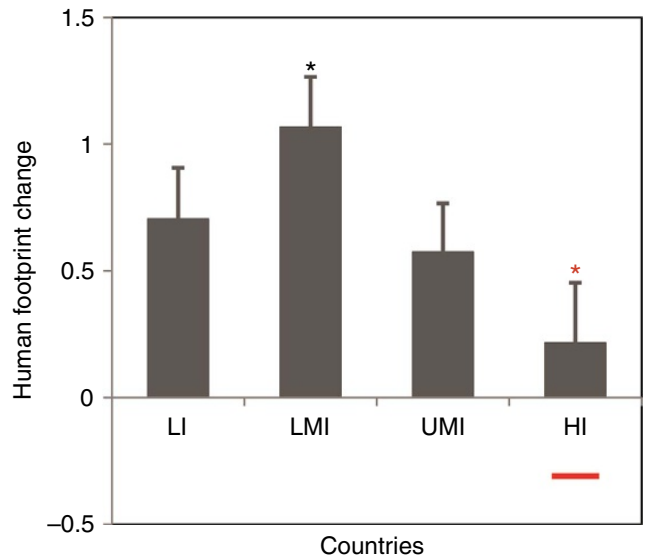

Figure 6 | Change in human footprint across countries grouped by income level. Average change in the human footprint over the 1993 to 2009 period for low-income ( $L I, n=36)$, lower-middle-income ( $L M I$, $n=42)$, upper-middle-income (UMI, $n=44)$ and high-income $(\mathrm{HI}, n=51)$ countries $^{33}$. The horizontal red bar below the $\mathrm{HI}$ column shows the average change for the wealthiest countries $(n=24)$, defined as those with $>\$ 30,000$ per person GDP at PPP in 2009. Black bars show standard errors and coloured asterisks denote statistical differences. pressures $^{39}$. Restoration may be particularly beneficial where pressures have arisen only recently, as the time-lags before biodiversity declines could mean that many species could still be saved ${ }^{40}$. Our analyses also highlight the importance of the Amazon basin as a highly specious and still largely intact system, but one now susceptible to accelerated pressures following recent policy changes ${ }^{41,42}$.

We found that some countries, particularly wealthy countries and those associated with high urbanization and low corruption, have been undergoing rapid economic growth while simultaneously reducing their human footprint. Most encouragingly, these countries are net exporters of agricultural and forestry products, and by this measure are not simply exporting their demand for food and fibre (and the associated local pressures) to other countries. These results are encouraging for the future as countries continue to expand economically and increase their rates of urbanization. We caution that these findings must be viewed as preliminary for two primary reasons. First, we are using the value and volume of trade as a proxy for the international 'trade' in human pressures. This combined measure of trade may hide differences among agricultural and forestry products in their production footprint. Second, we did not account for the broader suite of exportable environmental pressures, such as those associated with mineral products, manufactured goods and energy ${ }^{43}$.

Moreover, our work is subject to three general limitations. First, like all attempts to map cumulative pressures we did not fully account for all human pressures. Some of the missing and static pressures, such as invasive species and pollution, may be closely associated with pressures we did consider ${ }^{44}$, and therefore their inclusion may not affect our overall results. Second, a lack of available data resulted in three of our pressures being static through time, which would cause an underestimation of human footprint expansion if these pressures expanded at a higher than average rate. We were able to determine the sensitivity of our results to treating pasture lands, which are one of the most spatial extensive human pressures. Using dynamic pasture data at the national scale changed our national level results on average by $2 \%$, and did not change our findings qualitatively (Supplementary Table 2). Third, the human footprint measures the pressure humans place on nature, not the realized state or impacts on natural systems or their biodiversity ${ }^{7}$. Significant scope exists to determine how natural systems respond to cumulating human pressures, and if nonlinearity or thresholds exist where pressures lead to accelerated impacts. In light of these limitations, we make all of our maps available for download ${ }^{73,74}$, including all our individual pressures should data users wish to include new data or alter the use of existing data to create alternate maps of human pressure.

Table 2 | Variables used to explain human footprint change across countries.

\begin{tabular}{|c|c|c|c|c|}
\hline \multirow[t]{2}{*}{ Variables } & \multicolumn{2}{|c|}{ HF decreasing } & \multicolumn{2}{|c|}{ HF increasing } \\
\hline & Mean & S.d & Mean & S.d \\
\hline Net trade (million \$) & 1,278 & 11,727 & $-1,765$ & 14,310 \\
\hline Net trade (million tons) & 16.78 & 74.72 & -7.36 & 63.02 \\
\hline Urban (\% population) & 76.64 & 12.50 & 69.60 & 16.89 \\
\hline HDI (non-income) & 0.84 & 0.07 & 0.79 & 0.09 \\
\hline Control of corruption & 1.02 & 1.06 & 0.26 & 0.93 \\
\hline
\end{tabular}

$\mathrm{HF}$, human footprint.

Values presented are means and s.d.'s for variables used to explain $\mathrm{HF}$ change for 73 rapidly growing economies. Data are summarized for countries where $\mathrm{HF}$ is decreasing (environmental improvement; $n=26$ ) and where $\mathrm{HF}$ is increasing (environmental deterioration; $n=47$ ). 
The human footprint continues to expand on Earth, but at an overall rate that is slower than the underlying rates of population and economic growth. These results are profound for nature and humanity. Still, the near ubiquity of the pressures we exert on nature highlight the enormous challenges involved in achieving continued socio-economic growth without widespread environmental degradation.

\section{Methods}

Overview. To create the human footprint we adopted the methods developed by Sanderson et al. ${ }^{14}$. To facilitate comparison across pressures we placed each human pressure within a $0-10$ scale (not all pressure range across the full 0-10 scale, details on the weightings for each pressure are provided in the flowing sections) and acquired data for the early 1990s (on average 1993) and 2009. The human pressures we considered included the following: (1) the extent of built environments; (2) crop land; (3) pasture land; (4) human population density; (5) night-time lights; (6) railways; (7) roads; and (8) navigable waterways. These pressures were weighted according to estimates of their relative levels of human pressure following Sanderson et al. ${ }^{14}$ and summed together to create the standardized human footprint for all non-Antarctic land areas. Pressures are not intended to be mutually exclusive, and many will co-occur in the same location. Three pressures only had data from a single time period, and these are treated as static and excluded from all trend analyses (Table 1). We tested the sensitivity of our results to these static data, and to the scoring scheme, results below. We used ArcGIS 10.1 to integrate spatial data on human pressures. Analyses were conducted in Goode's homolosine equal area projection at the $1 \mathrm{~km}^{2}$ resolution, yielding $\sim 134.1$ million pixels for Earth's terrestrial surface. For any grid cell, the human footprint can range between 0 and 50 .

Built environments. Built environments are human-produced areas that provide the setting for human activity. In the context of the human footprint, we take these areas to be primarily urban settings, including buildings, paved land and urban parks. Built environments do not provide viable habitats for many species of conservation concern, nor do they provide high levels of ecosystem services ${ }^{45,46}$ As such, built environments were assigned a pressure score of 10 .

To map built environments, we use the Defense Meteorological Satellite Program Operational Line Scanner (DMSP-OLS) composite images, which gives the annual average brightness of $30 \operatorname{arcsec}(\sim 1 \mathrm{~km}$ at the equator) pixels in units of digital numbers ${ }^{47}$. These data are provided for each year from 1992 to 2012 . We extracted data for the years 1994 (1993 was excluded due to anomalies in the data) and 2009, and all years were then inter-calibrated to facilitate comparison across the years ${ }^{48}$. Using the DMSP-OLS data sets, we considered pixels to be built if they exhibited a calibrated digital number $(\mathrm{DN})>20$. We selected this threshold based on a global analysis of the implications of a range of thresholds for mapped extent of cities ${ }^{49}$, and visual validation against Landsat imagery for 10 cities spread globally.

Population density. Many of the pressures humans impose on the environment are proximate to their location, these include pressures such as disturbance, hunting and the persecution of non-desired species ${ }^{50}$. Moreover, even low-density human populations with limited technology and infrastructure developments can have significant impacts on biodiversity, as evidenced by the widespread loss of various taxa, particularly mega fauna, following human colonization of previously unpopulated areas ${ }^{51}$

Human population density was mapped using the Gridded Population of the World data set developed by the Centre for International Earth Science Information Network ${ }^{52}$. The data set provides a $\sim 4 \mathrm{~km} \times \sim 4 \mathrm{~km}$ gridded summary of population census data for the years 1990 and 2010, which we downscaled to match the $1 \mathrm{~km}^{2}$ resolution of the other data sets. For all locations with more than 1,000 people $\cdot$ per $\mathrm{km}$, we assigned a pressure score of 10 . For more sparsely populated areas, we logarithmically scaled the pressure score using

$$
\text { Pressure score }=3.333 \times \log (\text { population density }+1)
$$

Nighttime lights. The high sensitivity of the DMSP-OLS ${ }^{47}$ data set provides a means for mapping the sparser electric infrastructure typical of more rural and suburban areas. In 2009, 79\% of the lights registered in the DMSP-OLS data set had a $\mathrm{DN}<20$, and are therefore not included in our built environments layers. However, these lower DN values are often important human infrastructures, such as rural housing or working landscapes, with associated pressures on natural environments.

To include these pressures, we used the inter-calibrated DMSP-OLS layers ${ }^{47}$. The equations for inter-calibrating across years are second-order quadratics trained using data from Sicily, which was chosen as it had negligible infrastructure change over this period, where DN average roughly 14. For our purposes, DN values of 6 or less were excluded from consideration before inter-calibration of data, as the shape of the quadratic function leads to severe distortion of very low DN values.
The inter-calibrated DN data from 1994 were then rescaled using an equal quintile approach into a $0-10$ scale. The thresholds used to bin the 1994 data were then used to convert the 2009 data into a comparable $0-10$ scale.

Crop and pasture lands. Crop lands vary in their structure from intensely managed monocultures receiving high inputs of pesticides and fertilizers to mosaic agricultures such as slash and burn methods that can support intermediate levels of many natural values ${ }^{53,54}$. For the purposes of the human footprint, we focused only on intensive agriculture because of its greater pressure on the environment, as well as to circumvent the shortcomings of using remotely sensed data to map mosaic agriculture globally, namely the tendency to confound agriculture mosaics with natural woodland and savannah ecosystems ${ }^{55}$.

Spatial data on remotely sensed agriculture extent in 1992 were extracted from the UMD Land Cover Classification ${ }^{56}$, and for 2009 from GlobCover ${ }^{57}$. Although intensive agriculture often results in whole-scale ecosystem conversion, we gave it a lower score than built environments because of less impervious cover.

Pasture lands cover 22\% of the Earth's land base or almost twice that of agricultural crops ${ }^{58}$, making them one of the most extensive direct human pressure on the environment. Land grazed by domesticated herbivores is often degraded through a combination of fencing, intensive browsing, soil compaction, invasive grasses and other species, and altered fire regimes ${ }^{59}$. We mapped grazing lands for the year 2000 using a spatial data set that combines agricultural census data with satellite derived land cover to map pasture extent ${ }^{58}$. We assigned pasture a pressure score of 4 , which was then scaled from 0 to 4 using the per cent pasture for each $1 \mathrm{~km}^{2}$ pixel.

Roads and railways. As one of humanity's most prolific linear infrastructures, roads are an important direct driver of habitat conversion ${ }^{60}$. Beyond simply reducing the extent of suitable habitat, roads can act as population sinks for many species through traffic-induced mortality ${ }^{61}$. Roads also fragment otherwise contiguous blocks of habitat, and create edge effects such as reduced humidity ${ }^{62}$ and increased fire frequency that reach well beyond the roads' immediate footprint ${ }^{63}$. Finally, roads provide conduits for humans to access nature, bringing hunters and nature users into otherwise wilderness locations ${ }^{64}$.

We acquired data on the distribution of roads from the global roads open access data set (gROADS) ${ }^{65}$, and excluded all trails and private roads, which were inconsistently mapped. The data set is the most comprehensive publicly available database on roads, which has compiled nationally mapped road data spanning the period 1980-2000. We mapped the direct and indirect pressure of roads by assigning an pressure score of 8 for $0.5 \mathrm{~km}$ out for either side of roads, and access pressures were awarded a score of 4 at $0.5 \mathrm{~km}$ and decaying exponentially out to $15 \mathrm{~km}$ either side of the road.

While railways are an important component of our global transport system, their pressure on the environment differs in nature from that of our road networks. By modifying a linear swath of habitat, railways exert direct pressure where they are constructed, similar to roads. However, as passengers seldom disembark from trains in places other than rail stations, railways do not provide a means of accessing the natural environments along their borders. To map railways we used the same data set as was used in the original footprint ${ }^{66}$, as no update of this data set or alternate source has been developed. The direct pressure of railways was assigned a pressure score of 8 for a distance of $0.5 \mathrm{~km}$ on either side of the railway.

Navigable waterways. Like roads, coastlines and navigable rivers act as conduits for people to access nature. While all coastlines are theoretically navigable, for the purposes of the human footprint we only considered coasts ${ }^{66}$ as navigable for $80 \mathrm{~km}$ either direction of signs of a human settlement within $4 \mathrm{~km}$ of the coast. We chose $80 \mathrm{~km}$ as an approximation of the distance a vessel can travel and return during daylight hours if travelling at $40 \mathrm{~km} \mathrm{~h}^{-1}$. As new settlements can arise to make new sections of coast navigable, coastal layers were generated for the years 1994 and 2009.

Large lakes can act essentially as inland seas, with their coasts frequently plied by trade and fishing vessels. On the basis of their size and visually identified shipping traffic and shore side settlements, we treated the great lakes of North America, Lake Nicaragua, Lake Titicaca in South America, Lakes Onega and Peipus in Russia, Lakes Balkash and Issyk Kul in Kazakhstan, and Lakes Victoria, Tanganyika and Malawi in Africa as we did navigable marine coasts.

Rivers were considered as navigable if their depth was $>2 \mathrm{~m}$ and there were signs of human settlements within $4 \mathrm{~km}$ of their banks, or if contiguous with a navigable coast or large inland lake, and then for a distance of $80 \mathrm{~km}$ or until stream depth is likely to prevent boat traffic. To map rivers and their depth we used the hydrosheds (hydrological data and maps based on shuttle elevation derivatives at multiple scales ${ }^{67}$ data set on stream discharge, and the following formulae from $^{68,69}$.

$$
\text { Stream width }=8.1 \times\left(\operatorname{discharge}\left(\mathrm{m}^{3} \mathrm{~s}^{-1}\right)\right)^{0.58}
$$

and

$$
\text { velocity }=4.0 \times\left(\text { discharge }\left(\mathrm{m}^{3} \mathrm{~s}^{-1}\right)\right)^{0.6} /(\text { width }(\mathrm{m}))
$$


and

$$
\text { Cross-sectional area }=\text { discharge } / \text { velocity }
$$

and

depth $=1.5 \times$ area $/$ width (assuming second order parabola as channel shape)

Navigable river layers were created for the years 1994 and 2009, and combined with the navigable coasts and inland seas layers to create the final navigable waterway layers. The access pressure from navigable water bodies was awarded a score of 4 adjacent to the water body, decaying exponentially out to $15 \mathrm{~km}$.

Validating the human footprint map. High-resolution images (median $=0.5 \mathrm{~m}$ ) were used to visually interpret human pressures at $3,5601 \mathrm{~km}^{2}$ sample points randomly located across the Earth's non-Antarctic land areas (Supplementary Fig. 1). For the visual interpretation, the extent of built environments, crop land, pasture land, roads, human settlements, infrastructures and navigable waterways was recorded using a standard key for identifying these features (Supplementary Note 1). Shape, size, texture and colour were important characteristics for identifying human pressures on the environment. Interpretations were also marked as certain or not certain, and the year and the resolution of the interpreted image were recorded. The 344 uncertain points were discarded, leaving 3,116 validation points. The human footprint score for each point was determined in ArcGIS, and the visual and human footprint scores were then normalized to a $0-1$ scale. The human footprint score was considered as a match to the visual score if they were within $20 \%$ of one another on the $0-1$ scale.

Sensitivity to static data sets and scoring. Three data sets (pasture lands, roads and railways) were treated as static pressures in our human footprint maps, as temporally inter-comparable data were not available for these pressures at a resolution ammenable to inclusion in the human footprint. If these pressures changed at rates that were higher or lower relative to the dynamic data sets, it could mean that our estimates of change in the human footprint were similarly lower or higher than actual change. We were able to test the sensitivity of maps to static data sets for pasture lands. We acquired data on national level changes in pasture extent from 1993 to 2009 from the United Nations Food and Agricultural Organization ${ }^{1}$.

Given that these data are national scale, we were able to determine how the analyses of change across countries would be perturbed if our static pasture data were replaced with dynamic data from the United Nations Food and Agricultural Association (UN FAO). Using the FAO data we were able to estimate the likely changes in the average contribution of pasture land pressures to changes in the human footprint across countries. This was done by multiplying the 1993 human footprint pasture pressure data by the country-level change in pasture extent from the FAO. We found inclusion of dynamic pasture pressures in this way did not change our national-scale analyses of changes in the human footprint. Our estimates of national level change in human footprint were very similar using the static or dynamic pasture data (Pearson's $R^{2}=99.8 \%, P<0.0001$ ) with an average perturbation from the static data with the dynamic data of just $\pm 2.6 \%$, and Uppermiddle-income countries still underwent the greatest increases and high-income countries underwent the least (Supplementary Table 1). We could not perform similar analyses for railways or roads, as changes in these linear infrastructures over time are simply not available, even at the national scale.

As described in the preceding sections, the eight pressures were scaled onto a $0-$ 10 scale according to estimates of their relative levels of human pressure following Sanderson et al. ${ }^{14}$, before summing together to create the standardized human footprint maps. We adopted the same scaling methods as Sanderson et al. ${ }^{14}$, as the original human footprint map has proven to be a strong predictor of a wide range of ecological phenomena, lending support to the scoring scheme. Similar to the sensitivity analyses for static data sets, we tested the sensitivity of our national-scale results to this scoring scheme.

We achieved by first determining the contribution of each of the eight pressures to the overall human footprint score for each country. We then randomly perturbed the score or 'weighting' for each pressure up by $50 \%$, down by $50 \%$ or keep it the same. After this random perturbation, we calculated the new nationalscale average human footprint score for each country by multiplying the old score by the random perturbation from, and then summed across pressures. The proportional change in national-scale human footprint was calculated by comparing the original and new human footprint values. Finally, we calculated the relative proportional change in national-scale human footprint by dividing the proportion change observed for a country by the global-scale change induced by the scoring perturbation. These steps were repeated 100 times.

We found that a $50 \%$ perturbation to the scoring of each pressure led to on average a $14.5 \%$ change in each country's national-scale human footprint. These national-scale changes also led to overall global-scale changes in human footprint values. When removing this global effect and focusing on only the relative changes across countries (such as would be done for the results contained in Fig. 6), we find that the $50 \%$ perturbations to the scores led to on average a $7.5 \%$ relative change in the national-scale human footprint values. These results demonstrate that national level human footprint values, especially when evaluating how countries compare relative to one another, are robust to how pressures are scored.
The human footprint national-level change. We compiled a number of nationalscale data sets to determine if over-the-horizon consumption, socio-economic transition, urbanization or governance can explain the difference in footprint trajectories among the most rapidly expanding economies. Rapidly developing economies were considered to be the top 50 percentile of countries for GDP at purchasing power parity growth per person over the 1993 to 2009 period $(n=73)$. Over-the-horizon consumption was measured as the trade balance (exports minus imports) for all agricultural (including crops and livestock) and forestry products in 2009, extracted from UN FAO ${ }^{70}$. Economic transition was measured in terms of economic development (2009 GDP per capita at PPP ${ }^{33}$ ) and human development (Non-income Human Development Index, $\mathrm{HDI}^{71}$. The non-income HDI takes into account the average achievements of a country for health and education. The degree a country has urbanized was measured in terms of the proportion of its population that lives in urban areas in 2009 (ref. 33). Overall governance capacity was measured in terms of a country's control of corruption ${ }^{72}$, and as a more direct measure of environmental governance, we used the proportion of a country's terrestrial area that has been set aside in protected areas ${ }^{33}$. We excluded all countries smaller than $1,000 \mathrm{~km}^{2}$ and those for which data were not available, leaving us with a 146 countries.

To explain the divergent environmental trajectories for the most rapidly expanding economies (countries within top 50 percentile for GDP at PPP per person change between 1993 and 2009) we fitted a general linear model at the country level, including the following variables: country area; GDP at PPP per person in 2009; control of corruption; proportion of country under protection; net trade in agricultural and forestry products (calculated as the sum of the value of agricultural and forestry exports minus that of imports); and the proportion of population in urban areas and non-income HDI. The proportion of urban population and non-income HDI was highly correlated (Spearman's rho $=0.72$ ) and they were therefore never included in the same models. We generated all possible subsets of the full model containing all variables and selected the most parsimonious one based on their Akaike information criterion (AIC) score. We also performed the same tests measuring trade in kilograms instead of dollars, but found that it did not alter our results.

Data availability. The $1 \mathrm{~km}^{2}$ resolution human footprint maps are stored in the Dryad Digital Repository (doi:10.5061/dryad.052q5) ${ }^{73}$, and may also be freely accessed through the Socioeconomic Data and Applications Center website (http://www.ciesin.org/). From Dryad the files may be downloaded as a single 7-zip file archive (7-Zip.org), which contains individual GeoTIFF data sets, an excel file with the validation data and a PDF with the validation key. The GeoTIFFs include the human footprint maps for 1993 and 2009, as well 14 additional GeoTIFFs of the processed data for each of the eight pressures from each time step. The individual pressure layers are provided should data users wish to rework these data to create alternate maps of human pressure for their particular needs or region. These data are described in ref. 74

\section{References}

1. Liu, J. et al. Complexity of coupled human and natural systems. Science 317, 1513-1516 (2007).

2. Costanza, R. et al. Changes in the global value of ecosystem services. Global Environ. Chang. 26, 152-158 (2014).

3. Kareiva, P., Watts, S., McDonald, R. \& Boucher, T. Domesticated nature: shaping landscapes and ecosystems for human welfare. Science 316, 1866-1869 (2007).

4. Steffen, W., Broadgate, W., Deutsch, L., Gaffney, O. \& Ludwig, C. The trajectory of the Anthropocene: the great acceleration. Anthropocene Rev. 2, 81-98 (2015)

5. Newbold, T. et al. Global effects of land use on local terrestrial biodiversity. Nature 520, 45-50 (2015).

6. Butchart, S. H. M. et al. Global biodiversity: indicators of recent declines. Science 328, 1164-1168 (2010)

7. Martins, J. H., Camanho, A. S. \& Gaspar, M. B. A review of the application of driving forces-pressure-state-impact-response framework to fisheries management. Ocean Coastal Manage. 69, 273-281 (2012).

8. Hansen, M. C. et al. High-resolution global maps of 21 st-century forest cover change. Science 342, 850-853 (2013).

9. Raiter, K. G., Possingham, H. P., Prober, S. M. \& Hobbs, R. J. Under the radar: mitigating enigmatic ecological impacts. Trends Ecol. Evol. 29, 635-644 (2014)

10. Halpern, B. S. \& Fujita, R. Assumptions, challenges, and future directions in cumulative impact analysis. Ecosphere 4, art131 (2013).

11. Woolmer, G. et al. Rescaling the Human Footprint: a tool for conservation planning at an ecoregional scale. Landscape Urban Plann. 87, 42-53 (2008)

12. Geldmann, J., Joppa, L. N. \& Burgess, N. D. Mapping change in human pressure globally on land and within protected areas. Conserv. Biol. 28, 1604-1616 (2014).

13. Halpern, B. S. et al. A global map of human impact on marine ecosystems. Science 319, 948-952 (2008).

14. Sanderson, E. W. et al. The human footprint and the last of the wild. Bioscience 52, 891-904 (2002) 
15. Di Marco, M. \& Santini, L. Human pressures predict species' geographic range size better than biological traits. Global Change Biol. 21, 2169-2178 (2015).

16. Yackulic, C. B., Sanderson, E. W. \& Uriarte, M. Anthropogenic and environmental drivers of modern range loss in large mammals. Proc. Natl Acad. Sci. USA 108, 4024-4029 (2011).

17. Safi, K. \& Pettorelli, N. Phylogenetic, spatial and environmental components of extinction risk in carnivores. Global Ecol. Biogeogr. 19, 352-362 (2010).

18. Seiferling, I., Proulx, R. \& Wirth, C. Disentangling the environmentalheterogeneity species-diversity relationship along a gradient of human footprint. Ecology 95, 2084-2095 (2014).

19. Hand, B. K., Cushman, S. A., Landguth, E. L. \& Lucotch, J. Assessing multi-taxa sensitivity to the human footprint, habitat fragmentation and loss by exploring alternative scenarios of dispersal ability and population size: a simulation approach. Biodivers. Conserv. 23, 2761-2779 (2014).

20. Beans, C. M., Kilkenny, F. F. \& Galloway, L. F. Climate suitability and human influences combined explain the range expansion of an invasive horticultural plant. Biol. Invasions 14, 2067-2078 (2012).

21. Steffen, W. et al. Planetary boundaries: guiding human development on a changing planet. Science 347, 1259855 (2015).

22. Willmott, C. J. \& Matsuura, K. Advantages of the mean absolute error (MAE) over the root mean square error (RMSE) in assessing average model performance. Clim. Res. 30, 79 (2005).

23. Viera, A. J. \& Garrett, J. M. Understanding interobserver agreement: the kappa statistic. Fam. Med. 37, 360-363 (2005).

24. Ramankutty, N., Foley, J. A., Norman, J. \& McSweeney, K. The global distribution of cultivable lands: current patterns and sensitivity to possible climate change. Global Ecol. Biogeogr. 11, 377-392 (2002).

25. Brooks, T. M. et al. Global biodiversity conservation priorities. Science 313, 58-61 (2006).

26. Pimm, S. L. et al. The biodiversity of species and their rates of extinction, distribution, and protection. Science 344, 987-1004 (2014).

27. Jenkins, C. N., Pimm, S. L. \& Joppa, L. N. Global patterns of terrestrial vertebrate diversity and conservation. Proc. Natl Acad. Sci. USA 110, E2602-E2610 (2013).

28. Myers, N., Mittermeier, R. A., Mittermeier, C. G., da Fonseca, G. A. B. \& Kent, J. Biodiversity hotspots for conservation priorities. Nature 403, 853-858 (2000).

29. BirdLife International and NatureServe. Birdlife Species Distribution Maps of the World (Birdlife International and NatureServe, 2012).

30. IUCN. IUCN Red List of Threatened Species. Version 2012.1 (2012).

31. Mittermeier, R. A. et al. Wilderness and biodiversity conservation. Proc. Natl Acad. Sci. USA 100, 10309-10313 (2003).

32. Gerland, P. et al. World population stabilization unlikely this century. Science 346, 234-237 (2014).

33. World Bank. World Bank Data Catalog http://datacatalog.worldbank.org/ (2014).

34. Dinda, S. Environmental Kuznets Curve hypothesis: a survey. Ecol. Econ. 49, 431-455 (2004)

35. Nepstad, D. C., Stickler, C. M. \& Almeida, O. T. Globalization of the Amazon soy and beef industries: opportunities for conservation. Conserv. Biol. 20, 1595-1603 (2006).

36. Achard, F. et al. Determination of deforestation rates of the world's humid tropical forests. Science 297, 999-1002 (2002).

37. FAO. Global Forest Resources Assessment 2010 (Food and Agriculture Organization of the United Nations, 2010).

38. Sloan, S., Jenkins, C. N., Joppa, L. N., Gaveau, D. L. A. \& Laurance, W. F. Remaining natural vegetation in the global biodiversity hotspots. Biol. Conserv. 177, 12-24 (2014).

39. Possingham, H. P., Bode, M. \& Klein, C. J. Optimal conservation outcomes require both restoration and protection. PLoS Biol. 13, e1002052 (2015).

40. Brooks, T. M., Pimm, S. L. \& Oyugi, J. O. Time lag between deforestation and bird extinction in tropical forest fragments. Conserv. Biol. 13, 1140-1150 (1999).

41. Godar, J., Gardner, T. A., Tizado, E. J. \& Pacheco, P. Actor-specific contributions to the deforestation slowdown in the Brazilian Amazon. Proc. Natl Acad. Sci. USA 111, 15591-15596 (2014).

42. Rodrigues-Filho, S. et al. Election-driven weakening of deforestation control in the Brazilian Amazon. Land Use Policy 43, 111-118 (2015).

43. Rees, W. Ecological footprints and appropriated carrying capacity: what urban economics leaves out. Environ. Urban. 4, 121-130 (1992).

44. Spear, D., Foxcroft, L. C., Bezuidenhout, H. \& McGeoch, M. A. Human population density explains alien species richness in protected areas. Biol. Conserv. 159, 137-147 (2013).

45. Tratalos, J., Fuller, R. A., Warren, P. H., Davies, R. G. \& Gaston, K. J. Urban form, biodiversity potential and ecosystem services. Landscape Urban Plann. 83, 308-317 (2007).

46. Aronson, M. F. J. et al. A global analysis of the impacts of urbanization on bird and plant diversity reveals key anthropogenic drivers. Proc. R. Soc. B 281, 20133330 (2014).
47. Elvidge, C. D. et al. Night-time lights of the world: 1994-1995. ISPRS J. Photogramm. Remote Sens. 56, 81-99 (2001).

48. Elvidge, C. et al. A fifteen year record of global natural gas flaring derived from satellite data. Energies 2, 595-622 (2009).

49. Small, C., Elvidge, C. D., Balk, D. \& Montgomery, M. Spatial scaling of stable night lights. Remote Sens. Environ. 115, 269-280 (2011).

50. Brashares, J. S., Arcese, P. \& Sam, M. K. Human demography and reserve size predict wildlife extinction in West Africa. Proc. R. Soc. Lond. B 268, 2473-2478 (2001).

51. Burney, D. A. \& Flannery, T. F. Fifty millennia of catastrophic extinctions after human contact. Trends Ecol. Evol. 20, 395-401 (2005).

52. CIESEN. Gridded Population of the World v3 (Center for International Earth Science Information Network, Columbia University, 2005).

53. Fischer, J. et al. Should agricultural policies encourage land sparing or wildlifefriendly farming? Front. Ecol. Environ. 6, 380-385 (2008).

54. Luck, G. W. \& Daily, G. C. Tropical countryside bird assemblages: richness, composition, foraging differ by landscape context. Ecol. Appl. 13, 235-247 (2003)

55. Herold, M., Mayaux, P., Woodcock, C. E., Baccini, A. \& Schmullius, C. Some challenges in global land cover mapping: an assessment of agreement and accuracy in existing $1 \mathrm{~km}$ datasets. Remote Sens. Environ. 112, 2538-2556 (2008).

56. Hansen, M. C., Defries, R. S., Townshend, J. R. G. \& Sohlberg, R. Global land cover classification at $1 \mathrm{~km}$ spatial resolution using a classification tree approach. Int. J. Remote Sens. 21, 1331-1364 (2000).

57. ESA. ESA GlobCover Project, led by MEDIAS, France. (2011).

58. Ramankutty, N., Evan, A. T., Monfreda, C. \& Foley, J. A. Farming the planet: 1. Geographic distribution of global agricultural lands in the year 2000. Glob. Biogeochem. Cycle 22, GB1003 (2008).

59. Kauffman, J. B. \& Krueger, W. C. Livestock impacts on Riparian ecosystems and streamside management implications-a review. J. Range Manag. 37, 430-438 (1984).

60. Trombulak, S. C. \& Frissell, C. A. Review of ecological effects of roads on terrestrial and aquatic communities. Conserv. Biol. 14, 18-30 (2000).

61. Woodroffe, R. \& Ginsberg, J. R. Edge effects and the extinction of populations inside protected areas. Science 280, 2126-2128 (1998).

62. Laurance, W. F., Goosem, M. \& Laurance, S. G. W. Impacts of roads and linear clearings on tropical forests. Trends Ecol. Evol. 24, 659-669 (2009).

63. Adeney, J. M., Christensen, Jr. N. L. \& Pimm, S. L. Reserves protect against deforestation fires in the Amazon. PLoS ONE 4, e5014 (2009).

64. Forman, R. T. T. \& Alexander, L. E. Roads and their major ecological effects. Annu. Rev. Ecol. Syst. 29, 207-301 (1998).

65. CIESEN. Global Roads Open Access Dataset, V1 (gROADSv1. Palisades, NY: NASA Socioeconomic Data and Applications Center (SEDAC), 2013).

66. NIMA. Vector Map Level 0 (VMAP0) (National Imagery and Mapping Agency, 1997).

67. Lehner, B., Verdin, K. \& Jarvis, A. New global hydrography derived from spaceborne elevation data. Eos. Trans. AGU 89, 93-94 (2008).

68. Bjerklie, D. M., Dingman, S. L., Vorosmarty, C. J., Bolster, C. H. \& Congalton, R. G. Evaluating the potential for measuring river discharge from space. J. Hydrol. 278, 17-38 (2003).

69. Bjerklie, D. M., Moller, D., Smith, L. C. \& Dingman, S. L. Estimating discharge in rivers using remotely sensed hydraulic information. J. Hydrol. 309, 191-209 (2005).

70. FAO. FAOSTAT Online Statistical Service (Food and Agriculture Organisation of the United Nations Rome, 2016).

71. UNDP. The Human Development Index. http://hdr.undp.org/en/statistics/hdi/ (2012).

72. WGI. World Governence Indicators. http://govindicators.org (2014).

73. Venter, O. Data from: The global Human Footprint maps for 1993 and 2009. Dryad Digital Repository. http://dx.doi.org/10.5061/dryad.052q5.

74. Venter, O. et al. Global terrestrial Human Footprint maps for 1993 and 2009. Sci. Data 3, 160067 (2016).

75. Olson, D. M. et al. Terrestrial ecoregions of the worlds: a new map of life on Earth. Bioscience 51, 933-938 (2001).

\section{Acknowledgements}

This work was supported by grants from the Wildlife Conservation Society, James Cook University and the Australian Research Council DP110102872 and DE140101624. We thank Neil Burgess, Jonas Geldman, Michelle Venter, Todd Stevens, Dan Segan, Joe Walston, John Robinson and Kim Fisher for their thoughtful feedback on this work. We thank Christopher Small for help with the nightlights data, and Alex De Sherbinin for help with roads and population data.

\section{Author contributions}

O.V. initially conceived the study; O.V., E.W.S. and J.E.M.W. coordinated its design, analysis and manuscript preparation; O.V., P.W., J.R.A., K.R.J., J.B., A.M. and B.M.F. conducted the analyses and all authors contributed ideas and critical feedback on the manuscript. 


\section{Additional information}

Supplementary Information accompanies this paper at http://www.nature.com/ naturecommunications

Competing financial interests: The authors declare no competing financial interests.

Reprints and permission information is available online at http://npg.nature.com/ reprintsandpermissions/

How to cite this article: Venter, O. et al. Sixteen years of change in the global terrestrial human footprint and implications for biodiversity conservation. Nat. Commun. 7:12558 doi: 10.1038/ncomms12558 (2016). (c) (i) This work is licensed under a Creative Commons Attribution 4.0 International License. The images or other third party material in this article are included in the article's Creative Commons license, unless indicated otherwise in the credit line; if the material is not included under the Creative Commons license, users will need to obtain permission from the license holder to reproduce the material. To view a copy of this license, visit http://creativecommons.org/licenses/by/4.0/

(C) The Author(s) 2016 